\title{
ALTERAÇÕES CLÍNICO-RADIOLÓGICAS PULMONARES PÓS-TRATAMENTO NA ESQUISTOSSOMOSE MANSONI AGUDA E CRÔNICA.
}

\section{Ênio Roberto Pietra Pedroso, José Roberto Lambertucci, Manoel Otávio da Costa Rocha, Dirceu Bartolomeu Greco, Cid Sérgio Ferreira, Pedro Raso e Davidson Pires de Lima.}

\begin{abstract}
Em $28,8 \%$ dos pacientes com esquistossomose mansoni tratados com oxamniquine ocorrem alterações radiológicas pulmonares caracterizadas por broncopneumonite (41\%), pneumonite (35\%), abaulamento do arco médio (17\%) e congestão pulmonar (7\%). As alterações são transitórias, com início até 3 dias após a terapêutica, em 50,7\% regredindo em 15 dias, completa e espontaneamente. Predominam na faixa etária entre os 4 aos 12 anos, não dependem, de padrão radiológico pré-tratamento, cor, sexo, naturalidade ou fase/forma da doença. As alteraçôes clínicas associadas às anormalidades radiológicas pós-tratamento são inexpressivas na forma aguda, toxêmica, enquanto na fase crônica surgem como estertores crepitantes e roncos. $O$ encontro de eosinófilos no escarro até o décimo segundo dia após o tratamento correlaciona-se como encontro de alterações radiológicas pulmonares pós-tratamento independentemente da faselforma da doença.
\end{abstract}

Palavras chaves: Esquistossomose. Oxamniquine. Tratamento. Complicações pulmonares.

A doença produzida pelo $S$. mansoni distinguese caracteristicamente por exteriorização clínica multifária e complexidade dos mecanismos fisiopatogenéticos.

A exteriorização anatomoclinica da infecção deve compreender a interação de pelo menos três ordens de fatores, todos ditados pela experimentação animal e pelo substrato da patologia humana: a) fase evolutiva em que se encontra o parasita, antes ou após a postura; b) órgão predominantemente lesado pelos vermes jovens ou maduros ou, ainda, pelos seus ovos; c) tipo e desvios quantitativos e qualitativos da reatividade orgânica geral e textrina, gerados pelos produtos da destruição de esquistossômulos, vermes adultos e ovos 1924 .

Ao lado desses fatores, considerados fundamentais, outros deverão ser invocados como co-responsáveis pelas alterações que acarretam no organismo

Núcleo de Estudos sobre Esquitossomose. Faculdade de Medicina da Universidade Federal de Minas Gerais. Financiado parcialmente pelo CNPq e FINEP.

Departamento de Clinica Médica da Faculdade de Medicina da Universidade Federal de Minas Gerais. Av. Alfredo Balena, 190, 30.000, Belo Horizonte, Minas Gerais, Brasil. Recebido para publicação em 16/4/1984. parasitado, modificando suas reações em face da infecção. Dentre eles, alguns próprios do hospedeiro (hábito constitucional, padrão alimentar, vigência de concausas mórbidas, estado imunitário, tratamento especifico ou cirúrgico), outros relativos ao parasita (intensidade de infecção, reinfecção, diversidade patogenética de cepas) e alguns outros envolvendo inter-relações mais complexas ${ }^{19}$.

No homem há controvérsia quanto aos efeitos da terapêutica sobre os órgãos do hospedeiro. Alguns autores ${ }^{4} 1314$ se apóiam em que o tratamento específico da esquistossomose na fase crônica precipita o advento do estado terminal da doença. Outros 27 enfatizam que todas as pessoas portadoras da esquistossomose mansoni ativa devem ser tratados especificamente, ressalvadas as contra-indicações. Segundo Mota-Santos e cols ${ }^{16}$, o tratamento que suprime a postura previne ou melhora a doença. Bina ${ }^{1}$ ressalva o efeito benéfico do tratamento específico mesmo após a reexposição do hospedeiro ao $S$. mansoni. $\mathrm{Na}$ forma aguda, toxêmica, o tratamento específico com ou sem uso concomitante de corticóides pode ser instituido com reais beneficios para o paciente 1115 , conduzindo à cura clínica da enfermidade em curto espaço de tempo, com ou sem concomitância de cura parasitológica 202125 .

Neste trabalho estudam-se as alterações do apa- 
Pedroso ERP, Lambertucci JR, Rocha MOC, Greco DB, Ferreira CS, Raso P, Lima DP. Alteraçóes clínico-radiológicas pulmonares pós-tratamento na esquistossomose mansoni aguda e crônica. Revista da Sociedade Brasileira de Medicina Tropical 18: 23-31, Jan-Mar, 1985

relho respiratório em pacientes apresentando fase aguda ou crônica da esquistossomose mansoni até o trigésimo dia após o tratamento especifico da infecção. Procurou-se correlacionar as alterações pulmonares com as fases ou formas da doença e com o conhecido até então sobre as alterações pós-tratamento da esquistossomose mansoni.

\section{MATERIAL E MÉTODO}

Foram examinados 59 pacientes, de 4 a 44 anos, de ambos os sexos, procedentes dos Estados de Minas Gerais e Bahia, portadores de várias formas da esquistossomose mansoni, todos tratados com oxamniquine, $20 \mathrm{mg} / \mathrm{kg}$, via oral, dose única (Tabelas 1 e 2).

Tabela 1-Distribuicão dos pacientes quanto ao sexo, cor, naturalidade

\begin{tabular}{|c|c|c|c|c|c|c|c|c|c|c|}
\hline \multirow{2}{*}{ Pacientes } & \multicolumn{2}{|c|}{ Sexo } & \multicolumn{3}{|c|}{ Cor } & \multicolumn{3}{|c|}{$\begin{array}{l}\text { Naturalidade } \\
\quad M G\end{array}$} & \multirow[t]{2}{*}{$B a$} & \multirow[t]{2}{*}{ Total } \\
\hline & $M$ & $F$ & $L$ & $F a$ & $M$ & Leste & $B H$ & $O$ & & \\
\hline Número & 39 & 20 & 19 & 35 & 5 & 32 & 18 & 4 & 5 & 59 \\
\hline
\end{tabular}

Li leucodermo, Fa: faiodermo, M: melanodermo, BH: Belo Horizonte, O: outras regiões de Minas Gerais, Ba: Bahia.

Tabela 2 - Distribuição dos pacientes em função da faixa etária e da forma anátomo-clínica da esquistossomose mansoni.

\begin{tabular}{|c|c|c|c|c|c|}
\hline \multirow{3}{*}{$\begin{array}{c}\text { Faixa etária } \\
\text { (anos) }\end{array}$} & \multicolumn{4}{|c|}{ Formas anátomo-clínicas } & \multirow{3}{*}{ Total } \\
\hline & \multicolumn{3}{|c|}{ Crônicas } & \multirow{2}{*}{$\begin{array}{c}\text { Aguda } \\
\text { Toxêmica }\end{array}$} & \\
\hline & $H E$ & $I$ & Total & & \\
\hline 12 & 8 & 1 & 9 & 4 & 13 \\
\hline 12 & 28 & 5 & 33 & 8 & 41 \\
\hline 44 & 4 & 0 & 4 & 1 & 5 \\
\hline Total & 40 & 6 & 46 & 13 & 59 \\
\hline
\end{tabular}

HE: hepatesplênica, I: intestinal

Avaliação clínica pré-tratamento. Constou de exame clínico geral procurando caracterizar: 1) forma anátomo-clínica da doença e suas repercussões sobre o organismo (em especial aparelhos respiratório e cardiovascular, presença ou não de hepatesplenomegalia e circulação colateral) e 2) contactos com águas naturais (freqüência e locais). Procurou-se enfocar, particularmente, os sinais e sintomas pertinentes ao aparelho respiratório, considerando-se como sintomas especificos dispnéia, dor retroesternal e dor torácica exacerbada ou não pelos movimentos da caixa torácica e, como sinais específicos tosse, expectoração, estertores crepitantes e subcrepitantes, roncos expiratórios, sibilos, tiragem intercostal e cianose central. $O$ critério utilizado para o diagnóstico da forma hepatesplênica (FHE) baseou-se na presença de hepatesplenomegalia ao exame clínico, por vezes confirmada à laparoscopia, e pela presença de varizes do esôfago, constatadas no estudo radioló- gico; em certos casos, recorreu-se à esplenoportografia ou à biópsia hepática.

Avaliação laboratorial pré-tratamento. Constou de exame das hemácias, hemoglobina, hematócrito, reticulócitos, esfregaço do sangue periférico, contagem de leucócitos (global e diferencial), plaquetas, hemossedimentação, eosinófilos no escarro, exame de urina (caracteres gerais, elementos anormais, sedimentoscopia), exame coprológico e/ou retossigmoidoscópico (com biópsia retal e oograma qualitativo), além de telerradiografia do tórax. Biópsia hepática e hemoculturas foram realizadas, em alguns casos, com o fim de verificar a possivel existência de concausas infectuosas, outras hepatopatias e, particularmente, salmonelose septicêmica prolongada. Para hemograma, leucograma (global e diferencial), plaquetas, contagem de eosinófilos no escarro usou-se a coloração de Leishman. Os caracteres gerais e elementos anormais 
Pedroso ERP, Lambertucci JR, Rocha MOC, Greco DB, Ferreira CS, Raso P, Lima DP. Alterações clínico-radiológicas pulmonares pós-tratamento na esquistossomose mansoni aguda e crônica. Revista da Sociedade Brasileira de Medicina Tropical 18: 23-31, Jan-Mar, 1985

urinários foram pesquisados pela fita "Labstix" e o exame coprológico foi realizado pelo método KatoKatz.

Avaliação clínica pós-tratamento. Consistiu na verificação da evolução clinica diária, incluindo a medição da temperatura axilar às 8,16 e 24 horas; na observação cuidadosa das repercussões cardiopulmonares; na palpação abdominal e hepatesplênica em particular. Da mesma forma que na avalição prétratamento, procurou-se tanto alterações clínicas gerais quanto aquelas peculiares ao aparelho respiratório, até 20 dias após o tratamento. As anormalidades clínicas foram comparadas antes e após o tratamento.

Avaliação laboratorial pós-tratamento. Constou de observação das hemácias, hemoglobina, hematócrito, reticulócitos, leucócitos (global e diferencial), caracteres do esfregaço sangüíneo, plaquetas, eosinófilos no escarro, exame de urina (caracteres gerais, elementos anormais, sedimentoscopia), no terceiro e quinto dias após o tratamento. A telerradiografia do tórax em PA e perfil foi realizada nos primeiro, terceiro, quinto e décimo dias após o tratamento. Os pacientes que apresentaram alteraçōes radiológicas foram acompanhados com telerradiografias seriadas nos décimo-quinto e trigésimo dias após o tratamento. Foram utilizados os mesmos métodos laboratoriais dos exames empregados no pré-tratamento.

Todo o estudo teve como objetivo básico a identificação de alterações radiológicas pulmonares que surgiram até 5 dias após o tratamento específico da

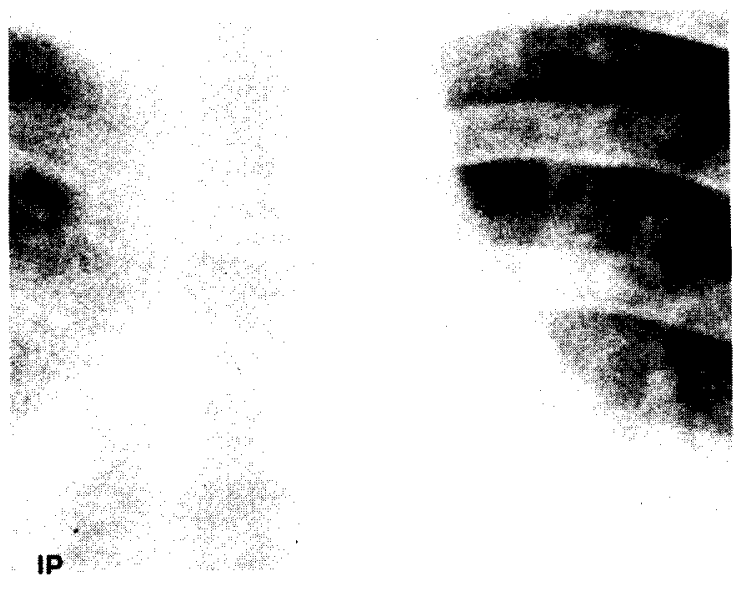

Figura 1-IP (forma intestinal), pré-tratamento: aspecto normal. helmintíase, em comparação com estudo radiológico similar anterior à terapêutica. A observação radiológica foi realizada por três investigadores, independentemente, em estudo simples-cego, sendo considerada alterada quando, pelo menos, duas de três impressões coincidissem. Todos os pacientes aceitaram espontaneamente participar deste projeto com as crianças tendo autorização explicita dos pais.

Os dados de cada variável foram comparados por meio dos testes do qui-quadrado e " $t$ " de Student. O nível minimo de significância foi de $5 \%$.

\section{RESULTADOS}

Após o tratamento especifico surgiram alterações radiológicas pulmonares em $28,8 \%$ dos casos, caracterizadas por broncopneumonite $(41 \%)$, pneumonite $(35 \%)$, abaulamento do arco médio (17\%) e congestão pulmonar (7\%). As alterações foram transitórias, não ultrapassando, a maioria, 30 dias de evolução, com início até 3 dias após a terapêutica e, em $50,7 \%$ dos casos, regredindo em 15 dias de forma completa e espontânea (Figuras de 1 a 10). Ocorrem, predominantemente, na faixa etária entre 4 e 12 anos. Não houve correlação entre o padrão radiológico pulmonar anterior ao tratamento e a evolução radiológica pós-tratamento, pelo menos até 30 dias de observação. A presença de alterações radiológicas prévias no grupo com alterações pulmonares póstratamento não se correlacionou com a persistência destas alterações no pós-tratamento, no mesmo periodo de acompanhamento já referido.
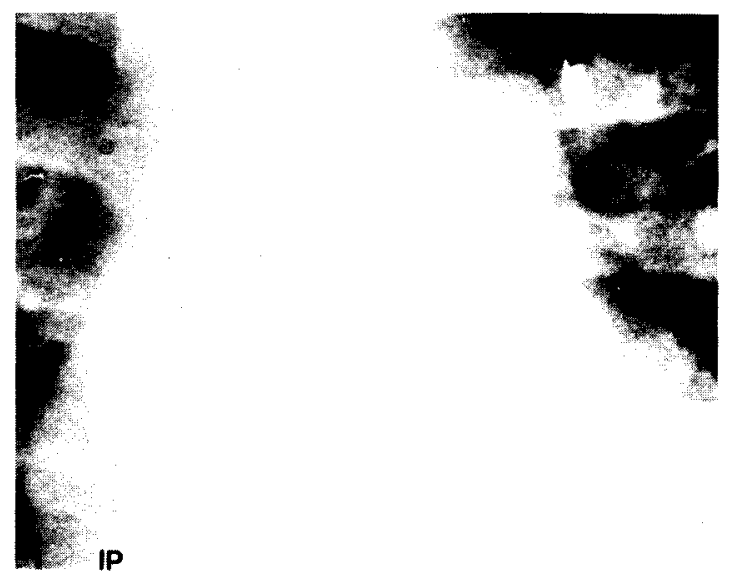

Figura 2-IP, 5.o dia pós-tratamento: arco médio convexo (seta). 
Pedroso ERP, Lambertucci JR, Rocha MOC, Greco DB, Ferreira CS, Raso P, Lima DP. Alteraçöes clínico-radiológicas pulmonares pós-tratamento na esquistossomose mansoni aguda e crônica. Revista da Sociedade Brasileira de Medicina Tropical 18: 23-31, Jan-Mar, 1985
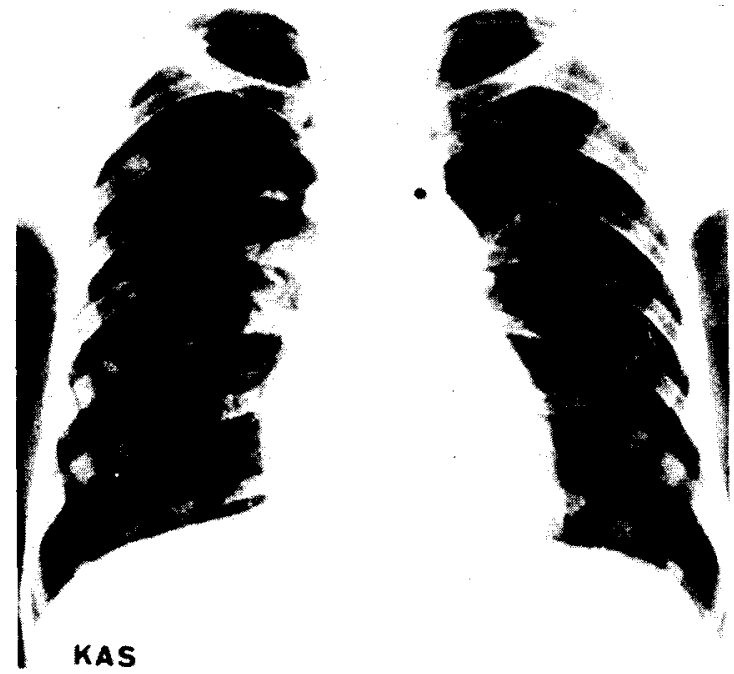

Figura 3-KAS (forma hepatesplênica), pré-tratamento: micronodulos nos campos superior, médio e inferior de ambos hemitóraces.

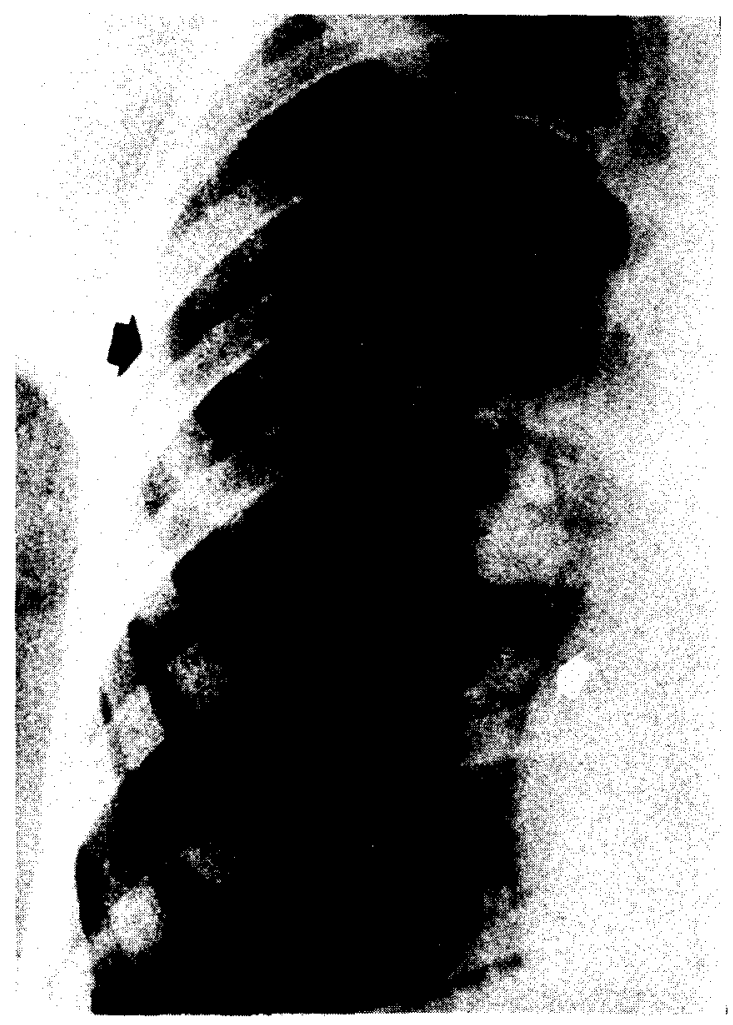

Figura 5-KAS, 4. dia pós-tratamento: mesmas alteraçóes observadas na figura 4 (setas).

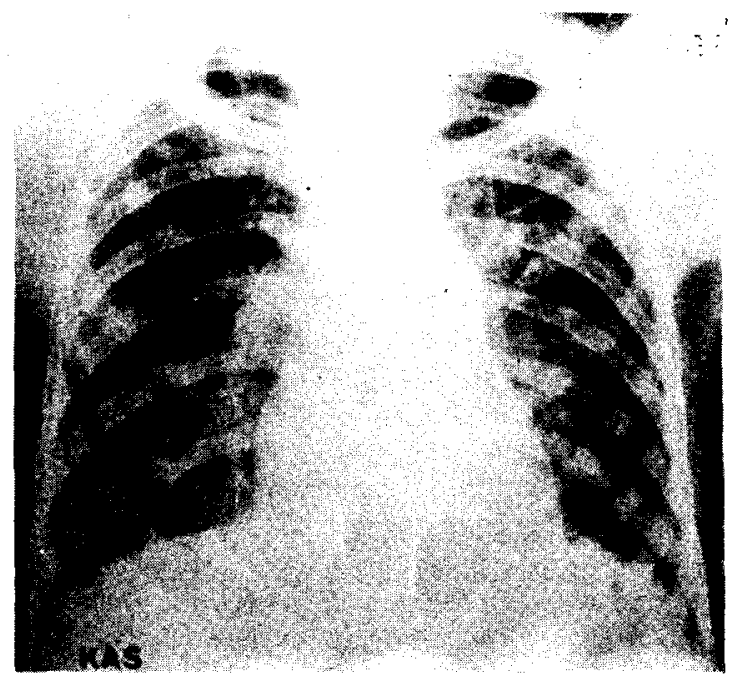

Figura 4-KAS, 3.o dia pós-tratamento: focos arredondados nos campos médio e superior de ambos hemitóraces com broncograma aéreo (tipo bronco-pneumónico).

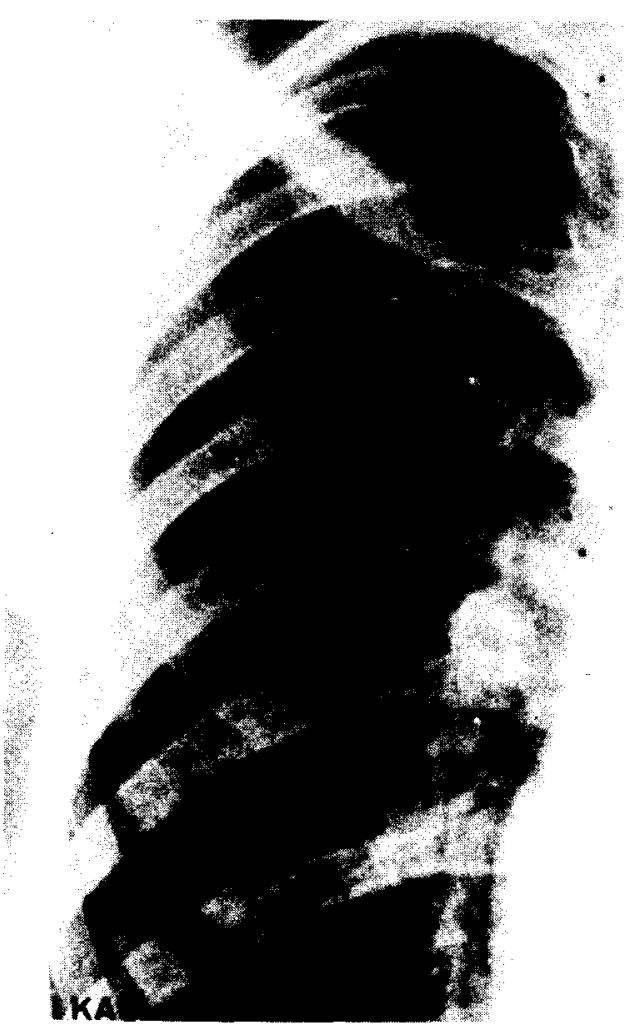

Figura 6-KAS, $11 .^{\circ}$ dia pós-tratamento: condensacões desaparecem. persiste a micronodulação. 

pulmonares pós-tratamento na esquistossomose mansoni aguda e crônica. Revista da Sociedade Brasileira de Medicina Tropical 18: 23-31, Jan-Mar, 1985
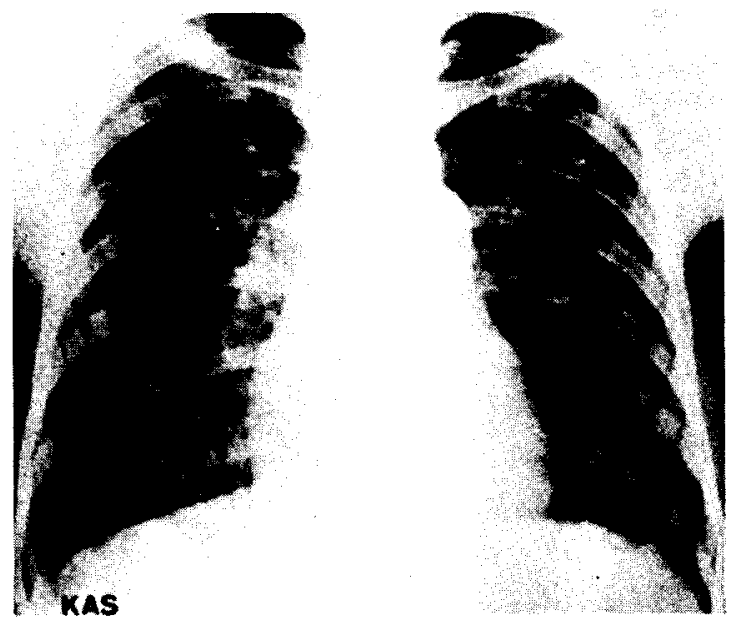

Figura 7-KAS 20.0 dia pós-tratamento: aspecto prétratamento.

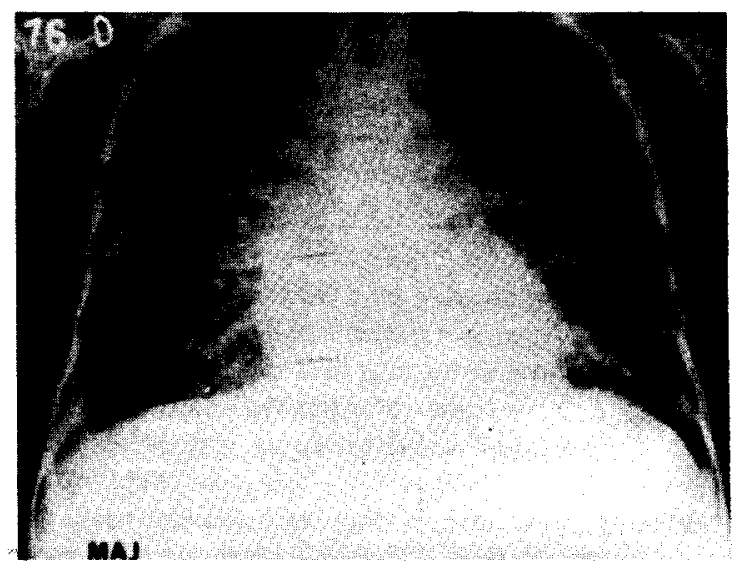

Figura 9-MAJ, 5.o dia pós-tratamento: linhas $A$ e $B$ de Kerley, aumenta a micronodulação nos campos médio e inferior do hemitórax direito, até a periferia.

Não houve associação entre as alterações radiológicas pulmonares pós-tratamento e a cor, sexo, naturalidade, época de tratamento, fase ou forma da doença.

Nos pacientes com alterações radiológicas pulmonares pós-tratamento, independentemente da fase da doença, foram significativos, entre os achados clinicos, os sinais gerais e sintomas próprios do aparelho respiratório que surgiram na primeira semana após o tratamento. Considerando a fase da doença, observase que, na fase crônica, foi significativo o encontro de sinais gerais associados às alterações radiológicas pulmonares pós-tratamento. Nos pacientes em fase

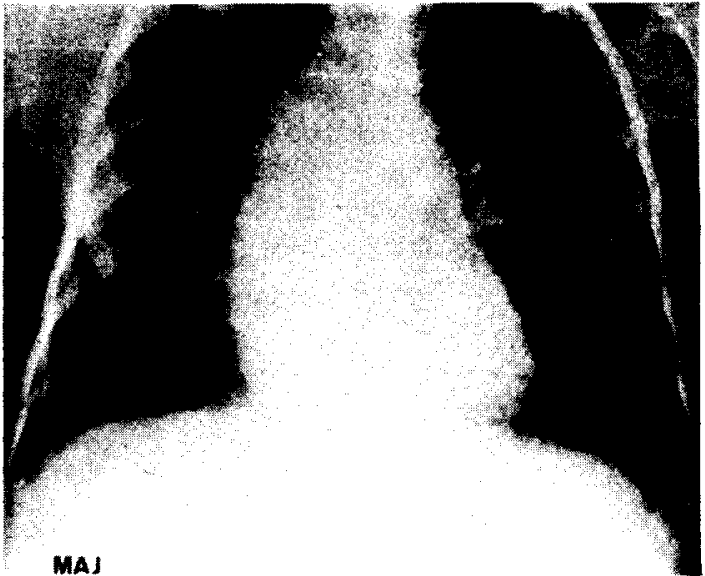

Figura 8-MAJ (forma hepatesplênica), pré-tratamento: micronódulos nos campos superior, médio, inferior de ambos hemitóraces (periferia pulmonar náo acometida). Arco médio convexo.

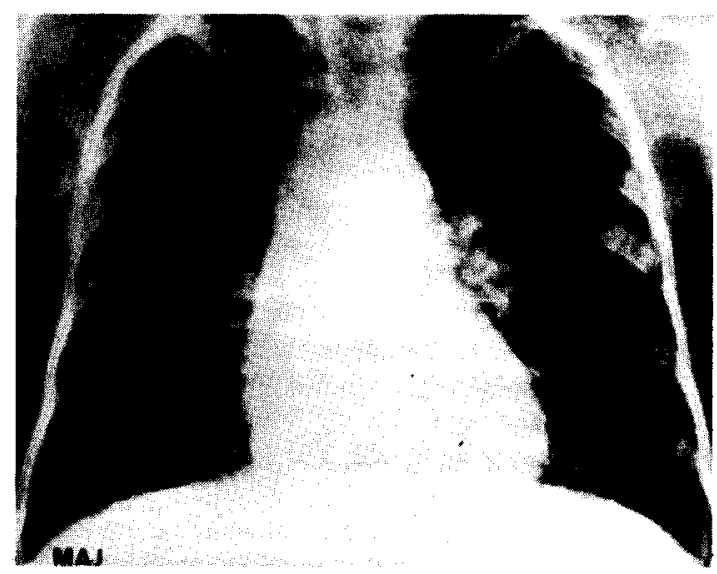

Figura 10-MAJ, 21. dia pós-tratamento: regressão quase completa das lesóes pré e póstratamento.

aguda não houve diferenças pré e pós-tratamento quanto aos achados clínicos gerais ou especificos do aparelho respiratório, nos grupos com ou sem alterações radiológicas pulmonares. Nos pacientes em fase crônica os sinais próprios do acometimento do aparelho respiratório, que se associaram com as alterações radiológicas foram estertores crepitantes e roncos. Dor retroesternal, dor torácica, dispnéia, febre, tosse, tiragem intercostal, sibilos, estertores subcrepitantes e rinorréia, não se associaram às alterações radiológicas pulmonares pelo menos até 15 dias após tratamento.

A presença de varizes ao estudo radiológico contrastado do esôfago não se associou às alterações 
Pedroso ERP, Lambertucci JR, Rocha MOC, Greco DB, Ferreira CS, Raso P, Lima DP. Alteraçóes clinico-radiológicas pulmonares pós-tratamento na esquistossomose mansoni aguda e crónica. Revista da Sociedade Brasileira de Medicina Tropical 18: 23-31, Jan-Mar, 1985

radiológicas cardiopulmonares nem influenciou os achados clínicos gerais até 15 dias após o tratamento.

O encontro de eosinófilos no escarro até 012 . dia após o tratamento correlacionou-se com encontro de alteraçoès radiológicas pulmonares pós-tratamento nos pacientes em fase aguda e crônica.

Não houve alteraçōes da criohemaglutinação, leucócitos sangüineos, uremia, creatininemia, glice- mia, eletrólitos séricos (sódio, cloreto, potássio), transaminases (oxalacética, pirúvica), bilirrubinas (direta e total), fosfatase alcalina, atividade de protrombina, eletroforese de proteínas séricas, depuraçāo de creatinina, exame de urina, eletrocardiografia, em correlação às alterações radiológicas pulmonares póstratamento (Tabelas 3 e 4).

Tabela 3 - Alterą̧óes radiológicas pulmonares pós-tratamento com oxamniquine

\begin{tabular}{lc}
$\qquad$ Total $=28,8 \%$ \\
\\
Broncopneumonite & $41 \%$ \\
Pneumonite & $35 \%$ \\
Abaulamento do arco médio & $17 \%$ \\
Congestâo pulmonar & $7 \%$ \\
\hline
\end{tabular}

Tabela 4 - Alterações radiológicas pulmonares pós-tratamento em função de condições clínicas e laboratoriais

Condiçōes clínicas e laboratoriais

Alterações radiológicas pulmonares pós-tratamento

\begin{tabular}{lrc} 
& Sim & Não \\
\cline { 2 - 3 } Cor, sexo naturalidade & NS & NS \\
Fase/forma & NS & NS \\
Sinais AR (estertores crepitantes, roncos) na fase crônica & S & NS \\
Evolução radiológico pós-tratamento & NS & NS \\
Padrão radiológico pré-tratamento & NS & NS \\
Varizes do esôfago & NS & NS \\
Eosinófilo no escarro & S & NS \\
Criohemaglutininas, leucócitos sangüineos, uremia, creatinemia, glicemia, & & \\
eletrólitos séricos (Na, K, Cl), SGOT, SGPT, bilirrubinas, fosfatase alcalina, & & \\
atividade de protrombina, eletroforese de proteinas séricas, depuração de & & \\
creatinina, urina (sumário), ECG. & NS & NS \\
\hline
\end{tabular}

S: significativo

NS: não significativo

\section{DISCUSSĀO}

Em individuos infectados com $S$. mansoni são freqüentes as alteraçōes pulmonares reveláveis pelo exame clínico-radiológico ${ }^{26}$. Podem ter caráter fugaz, sendo encontradas em todas as fases da parasitose, muitas associadas aos ovos ou vermes adultos 3623 . A despeito da fugacidade e do caráter autolimitado da maioria das alteraçōes não se pode afastar a possibilidade de ocorrência de lesões crônicas e duradouras em indivíduos predispostos, sujeitos à produção contínua de anticorpos contra antígenos do parasita. $O$ próprio tratamento da esquistossomose, segundo esta linha de pensamento, poderia levar à liberação dos antigenos e criar condições ideais de concentração para formar complexos solúveis e levar à sua deposição nos capilares renais, pulmonares e de outros órgãos.

As alterações radiológicas pulmonares aqui descritas sugerem acometimento de bronquiolos, alvéolos e vasos sangüíneos pulmonares e surgiram logo de imediato, ou até três dias após a terapêutica, depois da metabolização e eliminação da droga pelo organismo. É possível que o mecanismo responsável por estas anormalidades envolva duas formas de reação, imediata e tardia, podendo haver predor' 'nio de uma ou 

pulmonares pós-tratamento na esquistossomose mansoni aguda e crônica. Revista da Sociedade Brasileira de Medicina Tropical 18: 23-31, Jan-Mar, 1985

outra e complementação ou potencialização de efeito individual. Não eram migratórias, sem tendência à cronificação com resolução completa e espontânea, o que sugere acometimento de fácil depuração pelo organismo. Predominaram na faixa etária entre os $4 \mathrm{e}$ 12 anos, coincidindo com fase de intensas adaptações do hospedeiro ao seu meio, seja do ponto de vista imunológico, metabólico ou de síntese de seus tecidos $^{2}$.

A ausência de correlação entre o padrão radiológico pulmonar pré e a evolução radiológica póstratamento, indicam que, pelo menos do ponto de vista radiológico, as lesões presentes previamente não precipitam nem desencadeiam ảs alterações após o tratamento. $O$ pulmão serve de órgão efetuador de alguma reatividade do hospedeiro ao efeito terapêutico sobre o verme. A gravidade clínica geral e radiológica pulmonar pré-tratamento não deve ser parâmetro para prognosticar complicações pós-tratamento, pelo menos com oxamniquine.

A ausência de correlação entre alguns parâmetros raciais, de procedência do foco, fase ou forma da doença com as alterações radiológicas pulmonares pós-tratamento sugerem que o fenómeno responsável por estas alterações, até certo ponto, não se relacionam com aspectos genéticos do hospedeiro, cepa do parasita ou com presença de vias de comunicação entre os vermes no plexo mesentérico inferior e o local da efetuação fisiopatológica, sugerindo que seja processo gerai, que independe do hospedeiro e agente isoladamente mas, sim, de sua inter-relação.

Nos pacientes em fase crônica a presença de estertores crepitantes e roncos associou-se significativamente às alterações radiológicas pulmonares póstratamento. Essa correlação sugere que o acometimento pulmonar ocorre predominantemente ao nivel bronquiolo-alveolar. Os pacientes em fase aguda com alterações radiológicas pulmonares pós-tratamento não alteraram sua evolução clínica após a terapêutica. Tal fato se justifica pelos achados clínicos naturalmente mais exuberantes da forma aguda toxêmica da doença quando comparados com os da fase crônica17 18 .

A falta de correlação significativa entre a presença de varizes do esôfago com as alterações radiológicas pulmonares com os achados clinicos póstratamento realça a impressão de que as alterações pós-tratamento independem de vias vasculares hepatófugas ou facilitadoras entre o plexo mesentérico e o pulmão.
A ausência de associação entre as alterações radiológicas pulmonares e alteraçōes metabólicas, hepáticas, hematológicas, urinárias e eletrocardiográficas faz supor ser o processo efetuado no pulmão sem grande repercussão sistêmica com caráter benigno e fugaz. Não houve pois simultaneidade de alterações hepáticas, pelo menos visualizáveis pela bioquímica do sangue, com as 'alterações pulmonares ou com o tratamento 10 .

As anormalidades aqui estudadas parecem ser muito mais dependentes do tipo de reatividade do hospedeiro do que com a magnitude da mesma. Também sugerem que of fenômeno tende a se localizar no pulmão e, para tanto algum mecanismo deve facilitá-lo. Seria o pulmão o órgão efetor de alguma reação de hipersensibilidade ao verme, ao ovo, à droga? Seriam os macrófagos do pulmão já sensibilizados pelos esquistossômulos, numa fase anterior, responsáveis pelo reconhecimento de antígenos do verme adulto comuns aos esquistossômulos? Ao serem correlacionados com dados experiementais 822 exclui-se a droga como responsável isoladamente. Com os devidos cuidados de extrapolação para o homem ${ }^{12}$, estas mesmas alterações no camundongo são expressões de espessamento do septo interalveolar, peribronquite, pneumonite, congestão e hemorragia, associadas à deposição de $\mathrm{IgG}-\mathrm{C}_{3}$, sem presença de vermes ou ovos 22 .

Estas correlações são indícios de provável reação de hipersensibilidade pulmonar tipos $\mathrm{I}^{\mathrm{e} \mathrm{III}^{7}}$ com exsudação eosinofilica, desencadeada por antigenemia súbita provocada pelo tratamento.

A terapêutica provocaria a fase de equilibrio (injeção de antígeno), que seria seguida pela de catabolismo lento (degradação catabólica do antígeno), pela fase de eliminação imunológica com sintese de anticorpos (formação do complexo antigeno-anticorpo-complemento) e finalizando com presença de anticorpos livres ${ }^{5}$. A doença aguda é autolimitada, isto é, assim que o antígeno é eliminado cessa a formação de imunocomplexos. As alterações decorrentes desse processo, entretanto, podem ocorrer cronicamente desde que o antigeno seja injetado repetidamente, em quantidades superiores aos niveis de anticorpos circulantes, de modo a formar complexos solúveis com excesso de antigeno.

O quadro pulmonar, clínico-radiológico descrito pode ser entendido no grupo das pneumopatias eosinofilicas, especialmente da eosinofilia pulmonar simples, assemelhando-se à sindrome de Loeffler no coelho 9 . 
Pedroso ERP, Lambertucci JR, Rocha MOC, Greco DB, Ferreira CS, Raso P, Lima DP. Alterações clínico-radiológicas pulmonares pós-tratamento na esquistossomose mansoni aguda e crônica. Revista da Sociedade Brasileira de Medicina Tropical 18: 23-31, Jan-Mar, 1985

A eosinofilia pulmonar simples poderia ser o inicio de uma forma prolongada, seja dependente do ovo, verme morto e antigenos de pouca difusibilidade, ou associada a antigenos circulantes de grande difusibilidade do ovo, esquistossomulo, verme adulto vivo, produtos do metabolismo, outras secreções e excreções. Desta forma a terapêutica se justifica com o fim de diminuir a carga parasitária, mesmo que no póstratamento imediato hajam repercussões clínico-radiológicas pulmonares que alarmem o médico.

\section{SUMMARY}

Pulmonary alterations on $X$-rays were found in $28.8 \%$ of patients with schistosomiasis mansoni infection post-treatment with oxamniquine. They comprised bronchopneumonitis (41\%), pneumonitis (35\%), prominent medium arc (17\%), and pulmonary congestion (7\%). These alterations were transitory starting within 3 days after treatment. In $51 \%$ of the cases spontaneous, often complete, recoveryoccurred in 15 days. They were more common in patients, 4 to 12 years of age and did not depend on the pre-treatment radiologic pattern, race, sex, origin nor phase of the disease. In the chronic phase of the disease there were clinical manifestations (ronchi and rales) associated with the $X$-ray alterations, while in the acute, toxemic phase these were absent or mild. The presence of sputum eosinophils up to the 12th day post-treatment had a direct correlation with the appearance of $X$-ray abnormalities and did not depend on the phase or form of the disease.

Key-words: Schistosomiasis mansoni. Oxamniquine. Treatment. Pulmonary complications.

\section{REFERÊNCIAS BIBLIOGRÁFICAS}

1. Bina JC. Influência da terapêutica na evolução da esquistossomose mansoni. Tese de Mestrado. Universidade Federal da Bahia, Salvador, 1977.

2. Cantor H, Boyse EA. Functional subclasses of $T$ lymphocytes bearing different Ly antigens. I - The geration of functionally distinct $\mathbf{T}$ cells subclasses as a diferentiative process independent, of antigen. Journal of Experimental Medicine 141: 1376-89, 1975.

3. Coura JR, Coutinho SG, Moraes HM, Dias LB, Rodrigues NP, Silva JR. Esquistossomose pulmonar. Hospital 63: 31-50, 1963.

4. Coutinho AB. Objeções à prática do chamado "tratamento especifico" da esquistossomose mansoni. In:
Esquistossomose mansoni no Brasil (Doença de Manson - Pirajá da Silva). Sociedade de Gastroenterologia e Nutrição de São Paulo, São Paulo, p. 133-137, 1952.

5. Dixon FJ, Vasquez JJ, Weigle WO, Cochrane GC. Pathogenesis of serum sickness. Archives of Pathology 65: 18-23, 1958.

6. Gelfand M. Pulmonary schistosomiasis in the early "Katayama" phase of the disease. Journal of Tropical Medicine and Hygiene 69: 143-4, 1966.

7. Gell PG, Coombs RRA. Clinical aspects of immunology, Blackwell Scientific Publications, Oxford, 1968.

8. Greco DB. Infecção por Schistosoma mansoni e deposição de imune-complexos no pulmão. Estudo experimental. Tese de Doutorado. Faculdade de Medicina da Universidade Federal de Minas Gerais, Belo Horizonte, 1980.

9. Herbut PA, Kinsey FR. Transitory pulmọnary infiltrations (Loeffler's Syndrome) in rabbits. Archives of Pathology 41: 489-502, 1946.

10. Lambertucci JR. Ensaio terapêutico com a oxamniquine oral na esquistossomose mansoni crônica. Tese de Mestrado. Faculdade de Medicina da Universidade Federal de Minas Gerais, Belo Horizonte, 1983.

11. Lambertucci JR, Pedroso ERP, Souza DWC, Lima DP, Neves J, Salazar HM, Marinho RP, Rocha MOC, Coelho PMZ, Costa MFFL, Greco DB. The therapeutic efficacy of oral oxamniquine in the toxemic form of schistosomiasis mansoni: treatment of eleven individuals from two families, and experimental study. American Journal of Tropical Medicine and Hygiene 29:50-3, 1980.

12. Lichtenberg F. Studies on granuloma formation. III Antigen sequestration and destruction in the schistosome pseudotubercle. American Journal of Pathology 45: 75-93, 1964.

13. Magalhães Filho A. Anatomia patológica da esquistossomose mansoni. In: Esquistossomose mansoni no Brasil (Doença de Manson - Pirajá da Silva), Sociedade de Gastroenterologia e Nutrição de São Paulo, p. 125-132, São Paulo, 1952.

14. Magalhães Filho A. Patologia da esquistossomose mansônica. Considerações sobre a ação patogênica do verme morto. Anais da Faculdade de Medicina da Universidade do Recife 15: 95-110, 1955.

15. Marques RJ. A propósito da chamada fase toxêmica da esquistossomose mansónica. Anais da Faculdade de Medicina da Universidade do Recife 2: 243-56, 1957. 
Pedroso ERP, Lambertucci JR, Rocha MOC, Greco DB, Ferreira CS, Raso P, Lima DP. Alterafóes clínico-radiológicas pulmonares pós-tratamento na esquistossomose mansoni aguda e crônica. Revista da Sociedade Brasileira de Medicina Tropical 18: 23-31, Jan-Mar, 1985

16. Mota-Santos TA, Gazzinelli G, Ramalho-Pinto FJ, Pellegrino J, Silva WD. Immunodepression in mice following Schistosoma mansoni infection. Revista do Instituto de Medicina Tropical de São Paulo 18: 246-50, 1976.

17. Neves J. Estudo clínico da fase pré-postural da esquistossomose mansoni. Revista da Associação Médica de Minas Gerais 16: 1-16, 1965.

18. Neves J. Mesa redonda sobre CIBA 30644-Ba (Ambilhar). Folha Médica 53: 37-48, 1966.

19. Neves J, Raso P, Bogliolo L. Classificação clínicopatológica da esquistossomose mansoni. In: IV Congresso Brasileiro de Hepatologia, Resumo, Belo Horizonte, 1975.

20. Oliveira JL. $\mathrm{O}$ tratamento da esquistossomose mansoni no periodo toxêmico. Tese de Doutorado Faculdade Medicina Universidade Bahia, Salvador, 1957.

21. Oliveira CA, Zeitune JMR, Chamone DAF, Melo JRC, Salgado JA. Tratamento de casos da esquistossomose mansoni com o hycanthone. Revista do Instituto de Medicina Tropical de São Paulo 13: 202-12, 1971.

22. Pedroso ERP. Contribuição ao estudo da esquistossomose mansoni humana e experimental. Especial referên- cia às alterações clínico-radiológicas do pulmão após tratamento específico. Pulmão modelo imunopatológico da doença esquistossomótica. Tese de Doutorado. Faculdade Medicina da Universidade Federal de Minas Gerais, Belo Horizonte, 1982.

23. Prata A, Machado R. Alterações pulmonares observadas no tratamento antimonial da esquistossomose. Revista do Instituto de Medicina Tropical de São Paulo 2: 29-36, 1960.

24. Raso P, Bogliolo L. Patologia. In: Cunha (ed). A S Esquistossomose mansoni. Cap. 5, p. 77-130. Universidade de São Paulo, São Paulo, 1970.

25. Raso $P$, Neves J. Contribuição ao conhecimento da ação dos corticóides na forma toxêmica da esquistossomose mansoni. Anais da Faculdade de Medicina da Universidade de Minas Gerais 22: 167-80, 1965.

26. Santiago JM, Ratton JL. Quadro clínico das formas pulmonares. In: Cunha AS (ed) Esquistossomose mansoni. Cap. 6, p. 179-83, Universidade de São Paulo, São Paulo, 1970.

27. Sette $\mathbf{H}$. $\mathbf{O}$ tratamento da esquistossomose mansoni à luz da patologia hepática. Tese de Doutorado. Universidade Federal de Pernambuco, Recife, 1953. 